\title{
THE DIGITAL TRANSFORMATION OF MARKETING: IMPACT ON MARKETING PRACTICE \& MARKETS
}

\author{
Tom Gillpatrick ${ }^{1}$
}

date of paper receipt:

09.12.2019.

Review Article date of sending to review:

12.12.2019.

doi: 10.2478/eoik-2019-0023 date of review receipt:

19.12.2019.

UDK: 004.738.5:658.8

\begin{abstract}
Digital technology technologies and business practices are expected to radically transform the competitive landscape and society. Central to changing business practices is how digital technologies are transforming the practice of marketing which in turn is transforming the nature of markets globally. This paper, guided by the literature concerning the wave of digital disruption brought about by new technology, changes in consumer demand and new forms of business competition discusses industry level and macroeconomic impact of the digital transformation of marketing. The drivers of the digital transformation in marketing, the critical role of understanding the consumer value chain relative to marketing practice and the impact of changing business practices on the larger economy. A new model developed by (Teixeira, 2019) to assess consumer demand is described as a marketing practice innovation that can be used to gain new insights for innovation and marketing. These innovations in gaining market insights and in marketing strategies are discussed regarding implications for industry and macroeconomic policy. The authors call for calls for further research using this methodology to better understand how digital disruption is likely to impact firm competitiveness and the nature of larger global economy.
\end{abstract}

Keywords:

Industry 4.0, Digital Disruption, Digital Marketing, Trends in Consumer Behavior, Macroeconomics . 


\section{INTRODUCTION}

Peter Drucker famously stated, that, "There is only one valid definition of business purpose: to create a customer... and Because the purpose of business is to create a customer, the business enterprise has two- and only two basic functions: marketing and innovation. Marketing and innovation produce results; all the rest are costs." (Drucker and Maciariello, 2008, p. 30). An innovation has been defined as fresh idea that creates customer value, a fresh idea, that is widely accepted by the marketplace (Vaitheeswaran, Vijay, 2007). Economists generally believe that innovation is a primary driver for economic growth. Innovation can come from new ideas or technologies that leads to new products and/or business processes. While often studied separately marketing and innovation are a key factor for both business and policy makers in driving economic growth.

Researchers have reported (Teixeira, 2019) that new ways to study consumer buying processes given the digital revolution are critically important to achieving innovation success. At the heart of any business strategy is a plan to create, deliver and capture customer value. Marketing role within this process is to create customer value through the assessment of target customer needs, configuration of product/service offerings that are motivating to target customers, delivering those product/ service offerings using distribution and promotional channels and finding a way to capture customer value through innovative pricing strategies. An example, of an innovative pricing strategy was Bill Gates decision to license PC Operating System SW to individual users rather than to charge the computer manufacturer (IBM) a set price for its development and inclusion in its PC offering.

(The Digital Marketing Institute, 2019) reports, "When it comes to marketing, going digital has had massive consequences. Now properties of digital media such as more accurate metrics, combined with interactivity, have created whole new marketing opportunities. The exchange that can happen on social media, and even directly on ads, changes everything. With live ads, like live streams, consumers can be on social media and watch an influencer discuss a product. Now, instead of just watching a social influencer, viewers can interact by making comments, giving suggestions, and even getting responses back during that live stream. There is a level of engagement and interaction in 2019 that simply wasn't possible before digital transformation, and it changes the scope and nature of how marketers can approach their targets."

Increasingly a key component to both innovation and marketing is the digital transformation of our economy. The digital transformation of business is having a profound effect on marketing practices with far reaching impact on both micro and macro-economic levels. At the microeconomic level the digital transformation of marketing affects all aspects of the domain of marketing including product/service configuration; pricing; distribution and promotion activities. It involves nothing less than a complete reinvention of how firms innovate and create value in their "Go-to-market" strategies. At the macroeconomic level the digital transformation in marketing and the resultant marketing strategies impact national competitiveness, labor markets, innovation, antitrust, taxation among other factors.

The objective of this paper is to review the literature on trends in the digital economy, marketing and marketing practices and discuss the effects of a transformed practice of marketing on the competitive landscape.

\section{1. [GROWTH OF THE DIGITAL ECONOMY}

The definition of what constitutes the digital economy has evolved over time, this research uses a definition proposed in a recent OECD report by (Bukht and Heeks, 2017, p17) "That part of economic output derived solely or primarily from digital technologies with a business model based on digital goods or services." To this definition it has been suggested, that inclusion of broader trends, such as platformization, digital data and e-commerce, is needed for making policy evaluations. Exhibit 1 
below depicts a broad definition of the scope of the digital economy that is reported in the (OECD, 2017) report. (Foote, 2019) reports that, "the digital economy grew 9.9 percent annually over this 20-year period-4.3 times faster than the overall economy-and represented 6.9 percent of U.S. GDP as of 2017." How broad the measures used to estimate the size digital economy is important, when using broad measures, (UNCTAD 2019) the digital economy has been estimated to be up to $15.5 \%$ of U.S. GDP.

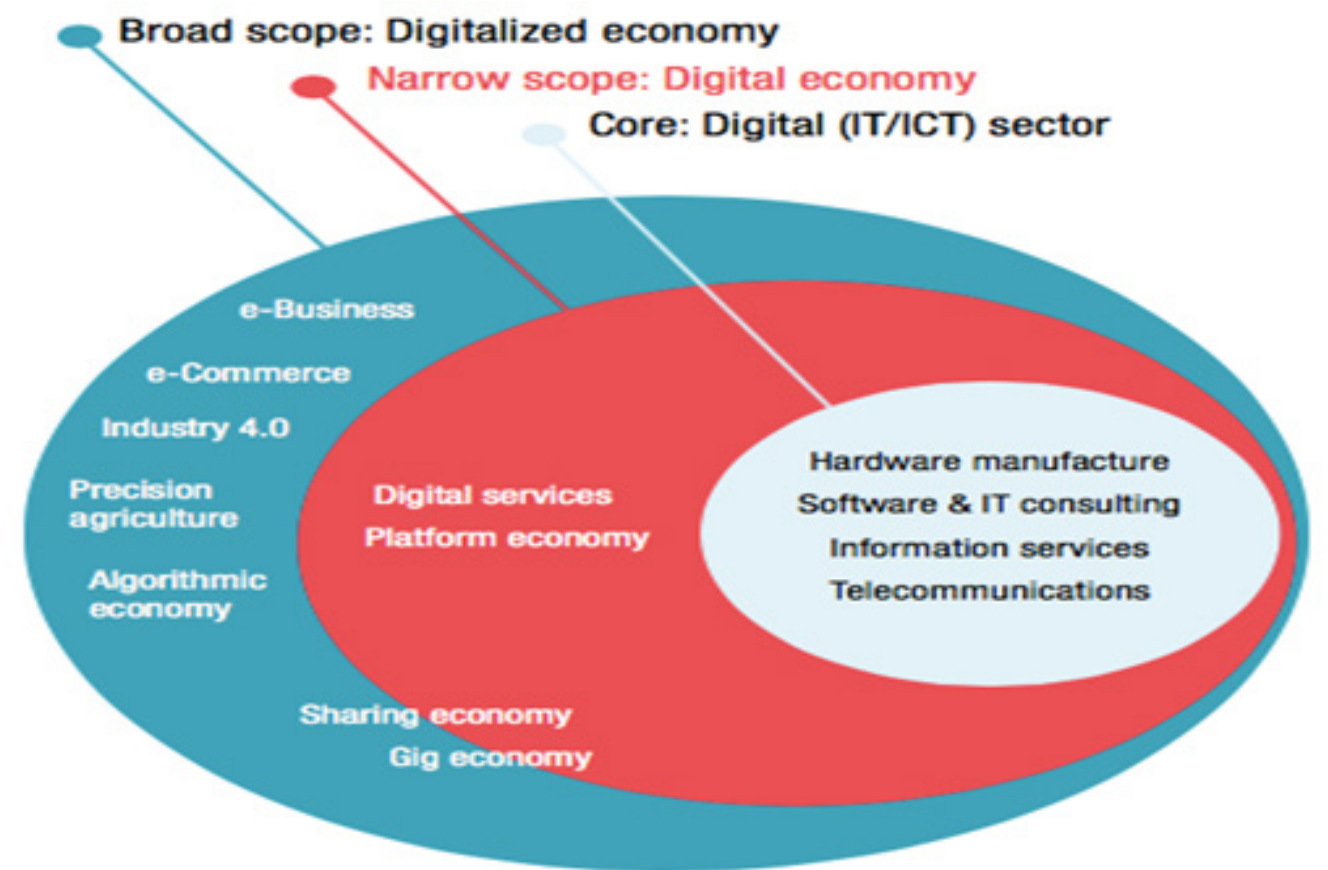

EXHIBIT ONE: SCOPE OF THE DIGITAL ECONOMY (UNCTAD, 2017)

That same reports notes that in 1992 internet data flows were about 100 Gigabytes per day, where it is forecasted these flows will be about 150,700 Gigabytes per second in 2022. Much of the growth of the digital economy is being fueled by new technologies such blockchain, artificial intelligence (AI) and data analytics, 3D printing, internet of things (IoT), 5G mobile, cloud computing, automation $\&$ robotics, among others. The value of global e-commerce has been estimated to be approximately $36 \%$ of global GDP in 2017, which is a $13 \%$ increase over the prior year (UNCTAD, 2017). The rapid growth globally of smart mobile phones and interconnectivity is also accelerating the growth and impact of the digital economy. (Rifkin, 2015) notes that in 2007 there 10 million sensors connected to the web, by 2013 that number had grown to 3.5 billion and it is estimated by 2030 the number of web enabled sensors will exceed 100 trillion. However, growth in investment into the digital economy is heavily concentrated in the USA and China which together comprise over $90 \%$ of the market valuation of the top 70 platform companies globally. The EU is third with about a $4 \%$ share of these top companies.

(Straub, 2019) notes that, "According to a 2019 World Economic Forum report, excitement over digitally enabled ecosystems is on the rise. While most of the focus has been on macroeconomic implications (for example, McKinsey research speculates that by 2025 over $30 \%$ of global economic activity could be mediated by digital platforms)." Additionally, he reports a McKinsey study that sees traditional industry clusters and value chain collapsing into a much smaller set of trillion dollar platform ecosystems that will impact all levels of the global economy.

Over time economic value has migrated away from physical products towards services as measured by sector impact on GDP. This is particularly true for more the developed economies, services' value added accounted for 74 percent of GDP in high-income countries in 2015, up from 69 percent in 1997. The growth rate of the service sector was even higher in less developed countries raising to 57 percent from 47 percent in that same time period. In the USA approximately 79 percent of economic value measured by GDP was linked to the service sector in 2017. Within the services 
sector, the digital economy has grown an even faster rate. Additionally, some experts suggest the size of the digital economy may be significantly underestimated using standard economic measures (OECD, 2019).

For physical products there has been a trend away from value coming from a physical product component to a greater percent of the perceived value of products coming from bundled services and intangible digital aspects. Some have referred to this process as the "dematerialization of value." (UN News, 2017) finds "that intangible capital accounted, on average, for 30.4 percent of the total value of manufactured goods sold throughout 2000-2014. Overall, income from intangibles increased by 75 per cent from 2000 to 2014 in real terms, amounting to $\$ 5.9$ trillion in 2014." This digital transformation of marketing is central to the growth and development of world economies. Digital technologies are also an important element in supporting the "servitization" of manufacturing processes, where manufacturing and services increasingly overlap (UNCTAD, 2019 , p.42). The ability of many digital services to easily scale given low marginal costs is also an important factor in the growth of dynamics of digital businesses.

\subsection{INNOVATION AND DRIVERS OF CHANGE IN MARKETING}

This new wave of digital disruption has been described as the third wave of digital disruption to impact our economy and many believe the effects will be much more significant than what industry has experienced to-date (Teixeira 2019). (Moeller et al., 2018) argue that, "Although many practices, products, and services have evolved...few enterprises have had their core businesses disrupted. But this is about to change." The coming wave of digital disruption brought about by this third wave is expected to have a much more fundamental impact because of the degree of interconnectivity it will bring among new technologies. The third wave of disruption is happening today and is transforming firms marketing and go-to-market strategies with wide range of economic effects. (Kagermann, 2015) states that, "Digitization-the continuing convergence of the real and the virtual worlds will be the main driver of innovation and change in all sectors of our economy." See Exhibit Two, for a description of these three waves of digital disruption affecting industry (Teixeira, 2019).

1. "Unbundling, the first wave of digital disruption, began in about 1995. Newspapers, once a source for articles, classifieds, and restaurant reviews, saw readers slowly drift away to Google, Craigslist, and Yelp. "Start-ups at the time decided to unbundle the newspaper," Teixeira said. "The product was unbundled, and the start-ups were offering their customers one part of the product."

The second wave, disintermediation, began in the early 2000s and affected products that were a combination of digital and physical. Instead of going to a travel agent to book hotels, flights, and tour activities, consumers took the process into their own hands. "You, the consumer of travel services, started going directly to the providers," he said.

Ten years later, is seems the third wave of disruption arrived. Decoupling is big, Teixeira explained, because it affects each step of the consumer's purchasing process: evaluating, choosing, purchasing, and consuming."

\section{EXHIBIT TWO: WAVES OF DIGITAL DISRUPTION (TEIXEIRA 2019)}

In looking at common threads across these waves of change, there are three key factors or drivers of change that have emerged. First, is the influence of new technology for communication, transportation \& industry infrastructure stemming from the digitalization of business processes. (Deloitte, 2017) in its Global Powers of Retailing report also found these factors as the key drivers of change in global marketing \& retailing. These new technologies have been characterized by increasing productivity of production and distribution and increased interconnections between 
technologies leading to lower costs and increased consumer convenience.

The second driver of innovation has been the development of new forms of competition that have evolved to offer consumers better value. These new forms of retail enterprises include a growing myriad of online options with a growing role of Omni-channel distribution. For example, (Rigby, 2011) describes Omni-channel in the December issue of the Harvard Business Review, entitled, "The Future of Shopping," which described Omni-channel distribution as a system where, "retailers will be able to interact with customers through countless channels, such as websites, physical stores, kiosks, direct mail, catalogs, call centers, social media, mobile devices, gaming consoles, televisions, networked appliances, home services, and more." Omni-channel relies on an integration on new technologies deployed in a manner to give consumer's $24 / 7$ access to products, information and communication. Online shopping which is currently about $10 \%$ of retail has been estimated to be about $40 \%$ by 2027, (World Economic Forum, 2017). Therefore, business capability is tightly linked to technological capabilities and the development of business models that have a new customer centric focus as opposed to a product centric focus.

The third driver is manifested by changing consumer preferences. Consumer demand is conditioned by new technology, new competitive forms along with societal changes is evolving at a rapid pace. Here changing demographics and consumer values are key drivers of changing consumer preferences. Arguably, changes in consumer demand are the most important of these drivers of disruption. Teixeira (2019) notes that it's not new technology or startups that causes market disruption, but that the real cause of disruption is changes in consumer demand. Technological inventions or new business models must be accepted by the market to become successful innovations. Thus, key to successful innovation is understanding the nature of demand and the preferences of consumers. The (World Economic Forum, 2017) conducted research on the future of retailing and concluded: "Consumers will be central to shaping the future direction of the industry. As their expectations around cost, choice, convenience, control and experience continue to climb, they will challenge the industry to keep up. For example, as AI is increasing deployed to enhance the customer service experience such AI assisted smart-speakers (Amazon Alexa and Google Home) or automated AI assisted customer service centers- it will be customer adoption of these technologies that will make or break the market success of each. At the same time, new and disruptive technologies will fundamentally impact the end-to-end industry value chain, benefitting both the industry and consumers."

The confluence of technology evolution leading to developments of AI/Data analytics, blockchain, three-dimensional printing (3D printing), the Internet of things (IoT), mobile technology, automation and robotics is fundamentally changing marketing practices regarding value creation, value delivery and value capture leading to the development of new business models and changes in consumer and broader macro-economic impact. Examples of how these technologies are having an impact in marketing practices include: co-creation of value between consumers and producers, the dematerialization of value in many products (the value-added component of digital content in cars, phones, etc.), omnichannel distribution and promotion strategies in delivering customer value and new value capture strategies that capture value by monetizing data and information obtained from social media, shopping behavior, etc.

IBM provides an example of the IoT can be used to gather data to be used in marketing efforts in Exhibit Three below. 


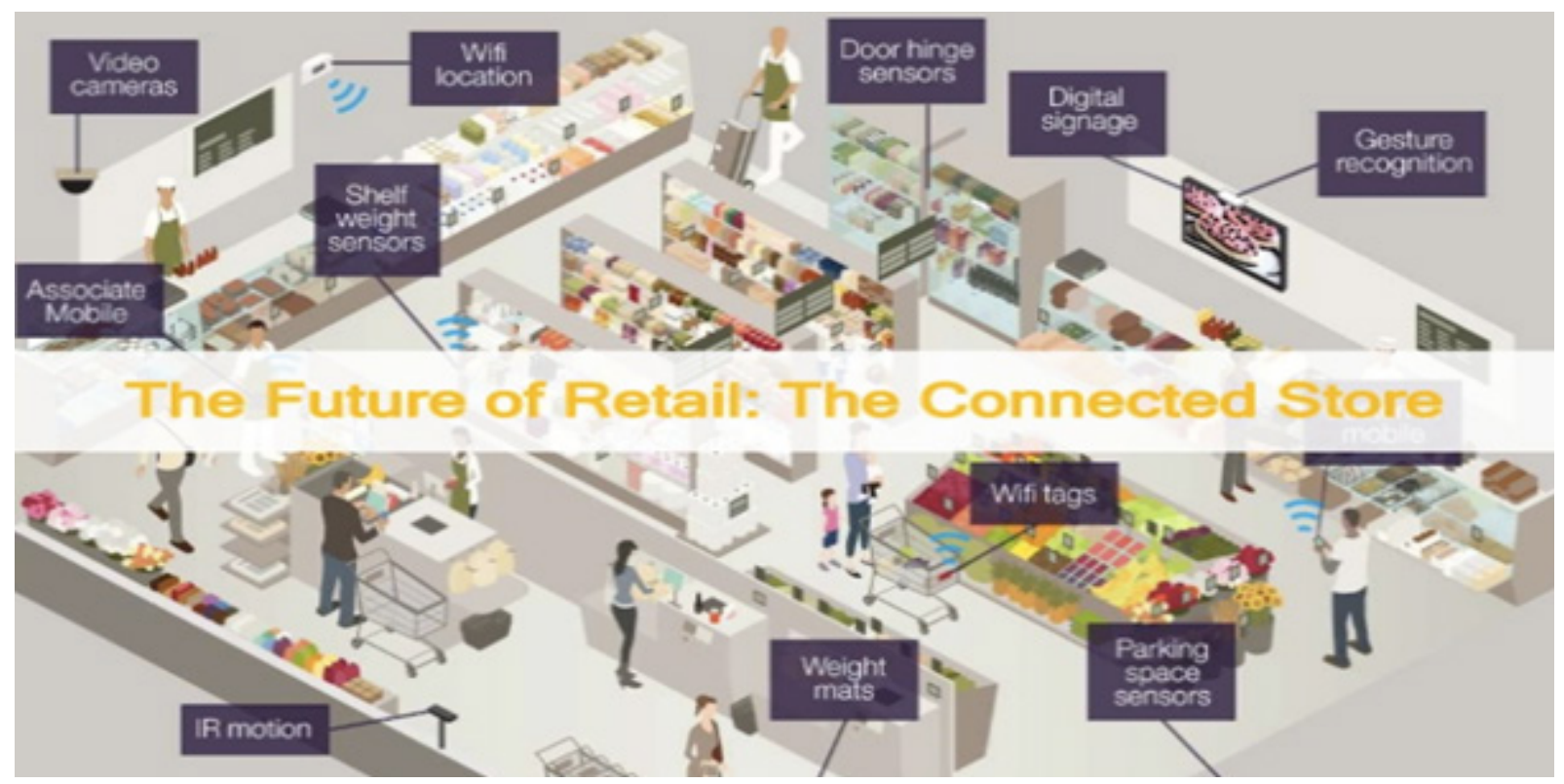

\section{EXHIBIT THREE: RETAIL CHANGES COMING FROM THE IOT HTTPS://WWW.IBM. COM/BLOGS/INTERNET-OF-THINGS/IOT-TRANSFORMING-RETAIL-INDUSTRY/}

As shown in Exhibit Three above there are a plethora of new technologies that are expected to impact retailers and consumers. Among those technologies (Accenture and the World Economic Forum 2017) estimate that four will have the greatest impact on retailers:

"Internet of Things will drive a high business value as it secures proprietary consumer data to create personalized experiences and delivers cost efficiencies in inventory-management. It will revolutionize the in-store experience for both consumers and organizations, providing unparalleled insights based on the data collected.

Autonomous vehicles/drones will bring cost savings from automated long-haul trucking of goods and last-mile delivery. These developments will also increase utilization, make deliveries faster and improve road safety.

Artificial Intelligence/machine learning can increase revenues through a deeper understanding of consumer behavior, while saving costs associated with supply chain optimization. In-store pricing and assortments will be optimized and, when combined with predictive recommendations, will clearly benefit consumers and the organization itself.

Robotics will drive cost savings through operational efficiencies, primarily in warehousing and distribution. Software bots can also work faster to complete simple and repetitive tasks. Robotics will enable higher utilization, greater flexibility, improved accuracy and faster transaction times."

\subsection{INNOVATION IN MARKETING: ANALYZING CONSUMER DEMAND}

For new innovations in products, processes and business practices there must be consumer acceptance. The behavior of consumers and industrial buyers is critical for the success of an innovation. This necessitates a deep understanding of how buyers initiate, search, evaluate, select and experience market offerings and methods of marketing. One key innovation in marketing practice is how analysis is used to study the nature of demand. (Ungerman et al., 2018) define "marketing innovation as doing something fundamentally new with ideas, products, services, or technologies based on market-based ideas that stem from a variety of customer desires." Thus, key to successful innovation leading to firm success and economic growth is an understanding of the nature of changing consumer demands.

(Court et al., 2009) introduced a new conceptual model to study consumer decision making. They labeled this new model, "The consumer decision journey (CDJ)." Their conceptualization was in 
response to a growing recognition that previous models) increasingly failed to capture what they described as, "all the touch points and key buying factors resulting from the explosion of product choices and digital channels, coupled with the emergence of an increasingly discerning, wellinformed consumer." See Exhibit Four: The Consumer Decision Journey. In the decade since it was introduced this model has been widely accepted both in academia and in industry. (Hamilton \& Price, 2019); (Lemon \& Verhoef, 2016). (Finneman \& Elzinga, 2017) report that Mckinsey has developed a database of over 125,000 consumer decision journeys' for over 350 products in over 30 different industries. They found the CDC model reflects a more complex reality of shifting choices, decision criteria, digital touchpoints important to consumers and key triggers. Its critical for brands to be in a consumers' initial consideration set, provide digital touchpoints and information at the right moments and provide trust/quality experience with a product or service.

Innovation in marketing also plays an increasingly important role in value creation in the economy. Value has migrated from physical assets to intangible assets among many corporate enterprises today. Marketing assets such as brand are growing as a percentage of company market value, reflecting the role that marketing has in a world that is becoming more customer centric as opposed to product centric. Indeed, when looking at the personal wealth of the world's most successful business-people such as Bill Gates and Jeff Bezos it appears the source of their success lies not in technical innovation but innovation in marketing. (Ungerman et al., 2018) studied the impact of marketing innovation and report that, "Business considers the greatest impact of innovative marketing in the context of Industry 4.0 to be the increase in enterprise competitiveness." Key to marketing innovation is an understanding of how customers perceived value and how products and services are adopted into their lives. These perceptions of value and lifestyle represent a moving target for marketers, and we need better processes to understand the needs of the market.

The stages of the CDJ (Awareness, evaluation, choosing, purchasing and consuming/experiencing) provide a rich framework which to study consumer processes throughout their journey experience. Increasingly firms develop detailed maps of the CDJ for different target customers and look to match marketing efforts (touch points) to guide and reinforce consumer associations of a positive experience with a brand. Insights from a better understanding of CDJ processes can be used to enhance the ability of a marketer to strengthen its business model to create, deliver and capture customer value.

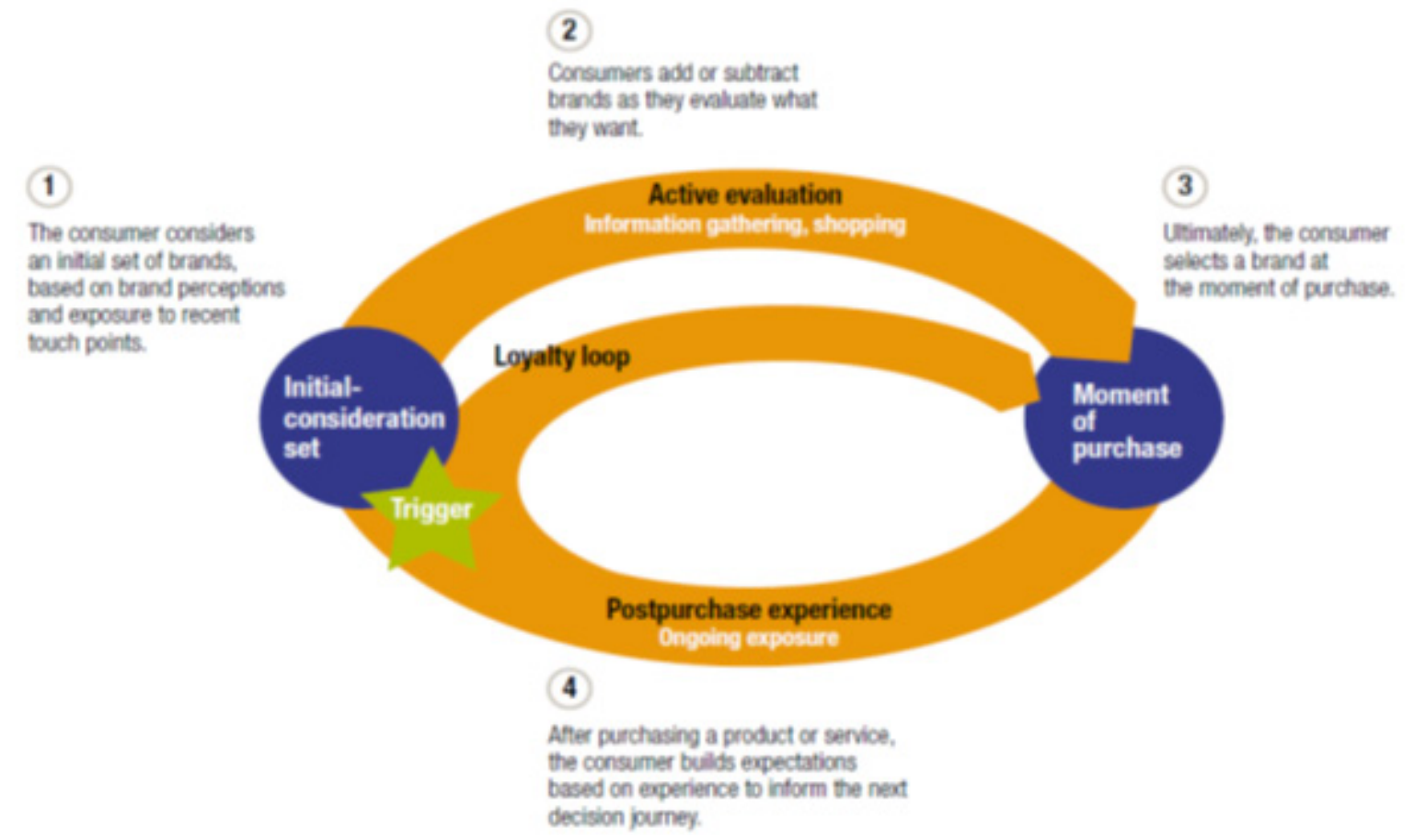

EXHIBIT FOUR: THE CONSUMER DECISION JOURNEY (CDJ) (MCKINSEY, 2009) 
Recently, (Teixeira, 2019) has created an analytic process that builds on the framework of the CDJ that represents a marketing innovation by mapping the "consumer value chain (CVC)." Where the value chain model developed by (Porter, 1985) primarily targets a set of value creating activities of firms. This approach is focused on understanding the value chain of consumers. Today, insights gained from this approach provides insights that can be used to decouple the CVC and give marketers opportunities to create and capture customer value utilizing these tools of disruption. It is critical for firms today to understand where opportunities to decouple and recouple consumer value exist:

"Unbundling, the first wave of digital disruption, began in about 1995. Newspapers, once a source for articles, classifieds, and restaurant reviews, saw readers slowly drift away to Google, Craigslist, and Yelp. "Start-ups at the time decided to unbundle the newspaper," Teixeira said. "The product was unbundled, and the start-ups were offering their customers one part of the product."

The second wave, disintermediation, began in the early 2000s and affected products that were a combination of digital and physical. Instead of going to a travel agent to book hotels, flights, and tour activities, consumers took the process into their own hands. "You, the consumer of travel services, started going directly to the providers," he said.

Ten years later, is seems the third wave of disruption arrived. Decoupling is big, Teixeira explained, because it affects each step of the consumer's purchasing process: evaluating, choosing, purchasing, and consuming" (Teixeira, 2019).

Teixeira's model maps all the activities a consumer engages in during the consumption process of the CDJ and assesses if those activities can be decoupled from each other. It is this decoupling of a consumer's value chain that has provided firms utilizing new technology and business models the insights to disrupt incumbent firms and entire industries. An overview of this can be seen in Exhibit Five: A typical consumer's value chain (CVC). Digital technologies have enabled new entrants in a market by unbundling, or decoupling and recoupling activities that create, delivery or capture consumer value in novel ways. Marketing value propositions that have previously bundled activities across the CDJ process, now face new competitors whose business models have decoupled two or more of those customer value chain activities and re-coupled those activities into their own new innovative business models. An example of this is shown in Exhibit Five, is where online retailers which target consumers who visit traditional bricks and mortar retailers (Best Buy), and use those stores as a showroom examining products, collecting information \& sales advice, and then finally purchasing products online from the disruptor retailer such as Amazon. Showrooming has become a major competitive threat for many traditional retailers given the increasing consumer willingness to adapt their shopping behavior using digital tools that decouple the consumer value chain.

Another example might be Uber business model, where it has decoupled the consumer's value chain $(\mathrm{CVC})$ focusing on making it easy for consumers to purchase and then utilize its ridesharing service. Amazon provides another example; research shows that in the U.S.A. today more than $50 \%$ of consumer product searches begin on Amazon. Retailers would be well served to study consumer value chains for opportunities to create, deliver and capture customer value thus remaining relevant for consumers. 


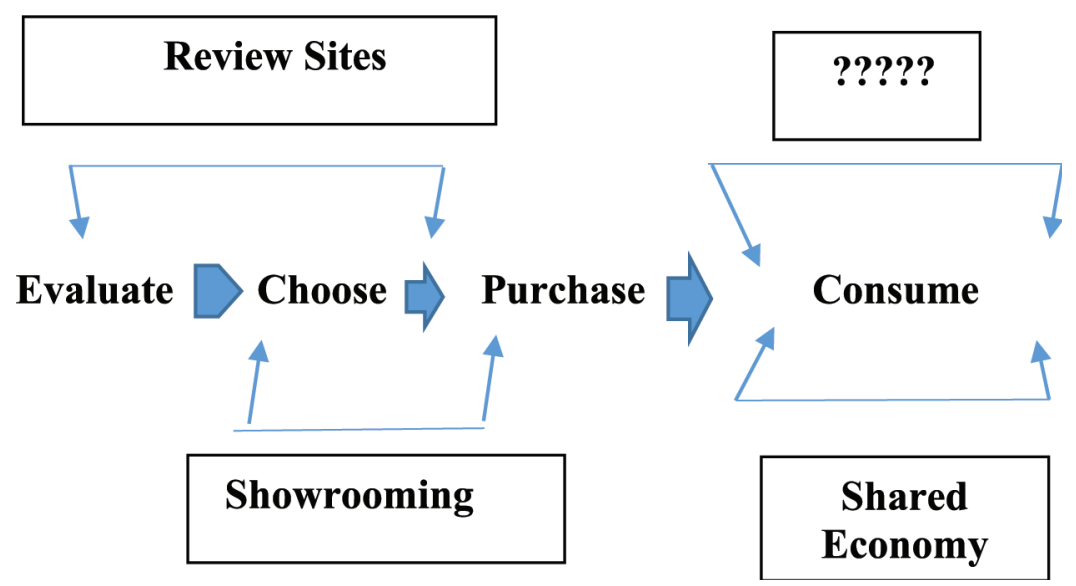

\section{EXHIBIT FIVE: A TYPICAL CONSUMERS VALUE CHAIN (CVC):}

Digital Disruption enables firms to Decouple Customer Value Delivery, (Teixeira, 2019)

Retail examples of decoupling include, a woman walking the aisles of a Costco store holding her smartphone to scan the products on the shelf while she narrates prices and opportunities to buy to thousands of online shoppers in China. She is providing a shopping service that has decoupled Costco's value proposition and recoupled it in a manner to provide value for consumers in China. How much value, this one woman has a million dollar per month business! Another example, is a retail company, also founded in Portland, Oregon called Hoopla Global which utilizes JD.com's shopping platform. Hoopla Global represents American manufacturers of CPG products wanting to sell in China, it maintains an online retail store on JD.com and actively promotes these products in China using a digital influencer strategy and ships using a "virtual free trade zone" model which in China features no tariffs, no special labeling, and direct delivery to Chinese customers from this virtual free trade zone. Additionally, Hoopla Global has created a backend digital supply chain using block chain technology that allows its vendors to easily prepare and ship their products to this virtual free trade zone in China. It provides both demand-side and supply-side value to its customers. It has effectively decoupled CVC activities and recoupled them in a manner that provides greater customer value and greater operational efficiency. These are examples of how digital technology is transforming marketing and changing supply and demand dynamics around the world. This methodology has identified three types of decoupling:

Value-creating activity: hearing a song you like on the radio.

Value-eroding activity: hearing a song you don't like.

Value-capturing activity: A promoted song or ad that the listener pays the station

The digital disruption largely comes from consumers adopting new technologies and new shopping behaviors from novel business models offered by both new market entrants and existing retailers with the foresight to reconfigure their business models in a customer centric manner. (Yohn, 2018) reports that a recent study among chief marketing officers (CMO's) found that only $14 \%$ believe that their companies are acting in a customer centric manner and even fewer of their customers (11\%) would describe them as customer centric. She argues that company culture is critical to achieving a customer centric business and describes a process for building a customer centric culture. To understand and unlock the customer value chain a customer centric as opposed to a product centric or a sales centric orientation is critically important. Amazon is often used as an example of a customer centric business whose organization structure and culture is designed around providing customer value. Managing with a customer-centric perspective, customers are viewed as a valuable firm asset and seeks to manage to maximize lifetime customer value.

Technology has become an important tool in driving CVC decoupling and allowing firms to recouple value producing activities in novel ways. There are literally thousands of novel new 
technologies that are vying to create value for marketers and their customers. These technology stretch across both the retailers and the customers value chains. Examples include robotics deployed both in the supply chain and consumer facing in stores and online, data analytic models that use big data and maching learning, smart sensors and displays throught the supply chain, AI deployed as management and customer interfacing tool. Key to whether these technologies can contribute value to consumer by ultimately lowering their costs or by improving the shopping experience. The Gartner group has developed a model that overviews new technologies and there stage of market acceptance, Exhibit Six, overviews technology adoption in retail.

(Teixeira, 2019) identified five steps that disruptors take to decouple the consumer journey:

Identify the consumption chain. Look at their customers to see what they're doing to get these products.

Look at the weak link. Where are customers satisfied with the activities?

Identify the type of the adjacent activities. Are these value-creating, capturing, or eroding activities? Increase the force of specialization. Reducing the monetary the effort or the time cost for the customer.

Anticipate the competitor response."

New entrants often enter the market and build share by lowering customer costs and providing customer convenience. New competitors like Bonobos and Warby Parker have offer customers value by providing convenience of in-home shopping, reducing shopper search costs and acquisition costs in the process. Disruptors often enter at the extremes of customer value perceptions by providing superior experiences or lower costs driving some traditional retailers to become, "stuckin-the middle" as (Porter, 1985) would describe where their value propositions are diminished by passionate shoppers searching for lower costs or better service experience or both. These "stuckin-the-middle" firms are disappearing from the competitive landscape at an increasing rate. An example is the struggles of the once might department stores such as Sears, Macy's and JC Penny. In all cases the customer's role in driving retail innovation through changing shopping behavior is critical. Following consumer trends has never been so important than it is today's rapidly changing world of consumer preferences

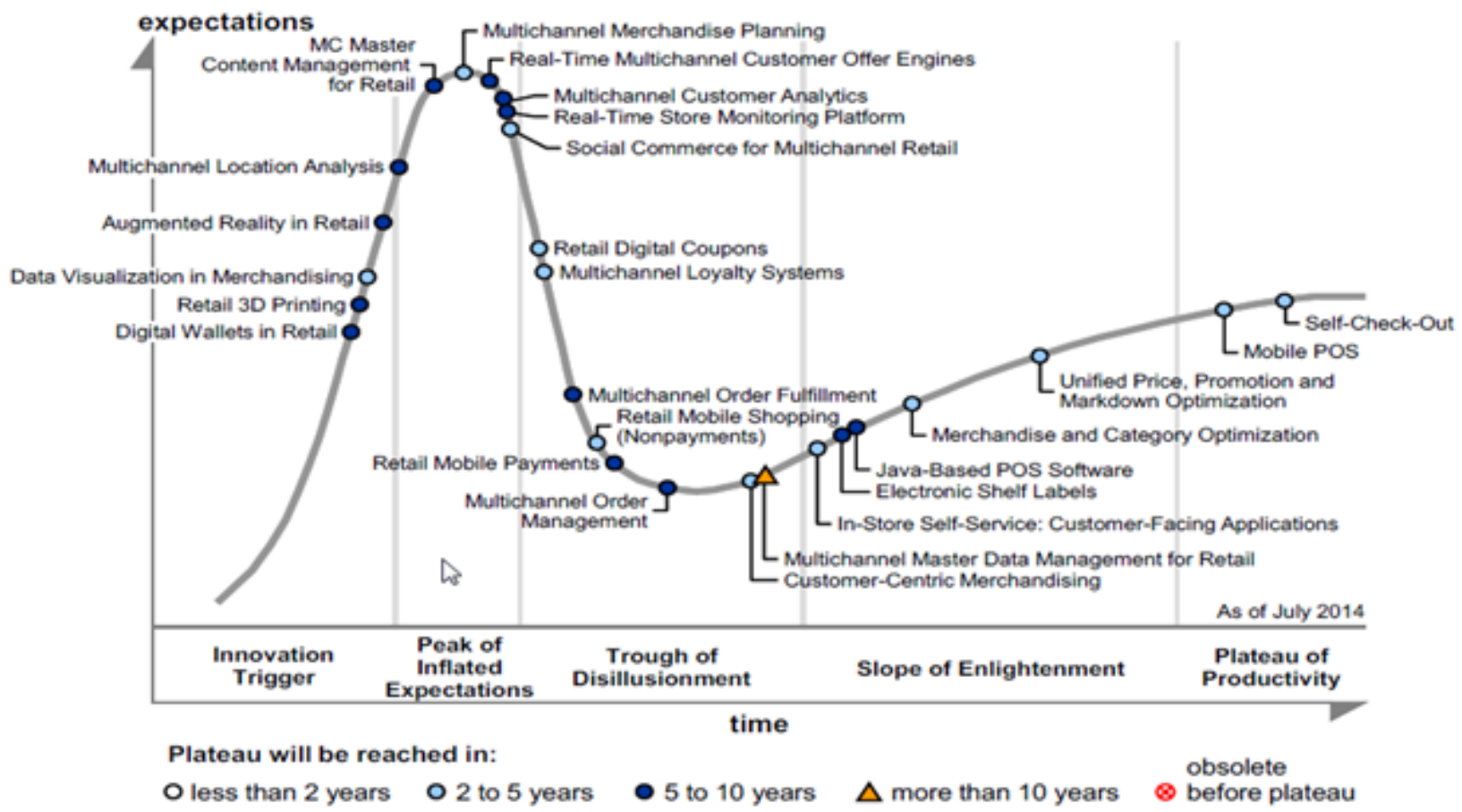

lource: Gartner (July 2014)

EXHIBIT SIX: GARTNER GROUP HYPER CYCLE FOR NEW RETAIL TECHNOLOGIES (2014) https://www.gartner.com/en/documents/3883976

Keeping up with consumer, technology and business model trends is a daunting task for marketers 
today. (Teixeira, 2019) proposes a novel way to monitor changes in the consumer value chain. While there are hundreds of industry market classifications detailed in census data, he observes only seven of these account for most of the consumer consumption. Additionally, because of the size and prominence of these leading industry categories they impact most other industries as well. He believes that following current trends in these seven can provide an accurate barometer of how to prepare for future trends in consumer preferences and shopping behavior.

What are these key consumer industries? He identifies them in terms of categories that that reflect the choices we make on how we live or lives. These include choices about where we live (housing and home goods), mobility (transportation), eating (food, drinks and preparation), what to wear (fashion, cosmetics and personal care), learning (education), entertainment (media, sports, electronics) and healthcare. In total, these seven categories make up $97 \%$ of consumption in America. He then uses U.S. Bureau of Labor Statistics data which has been collecting consumer data on how we consumer our time to determine an estimate of the amount of effort consumers expend each week in the seven consumption categories.

\section{EXHIBIT SEVEN: BELOW, DESCRIBES HOW CONSUMERS SPEND THEIR DISCRETIONARY TIME AFTER SLEEPING AND WORKING.}

The biggest allocation of times goes into entertainment about $39 \%$ of discretionary time allocation. However, effort spent to acquire this time for entertainment is relatively small as seen in the Figure below. Where there is a relatively high amount of effort required relative to the time spent in a category may be an indicator of potential for disruption according to Teixeira. For example, there is a large amount of effort required for moving about (transportation) he argues that business models that reduce consumer efforts (consumer costs) here may offer high potential for disruption.

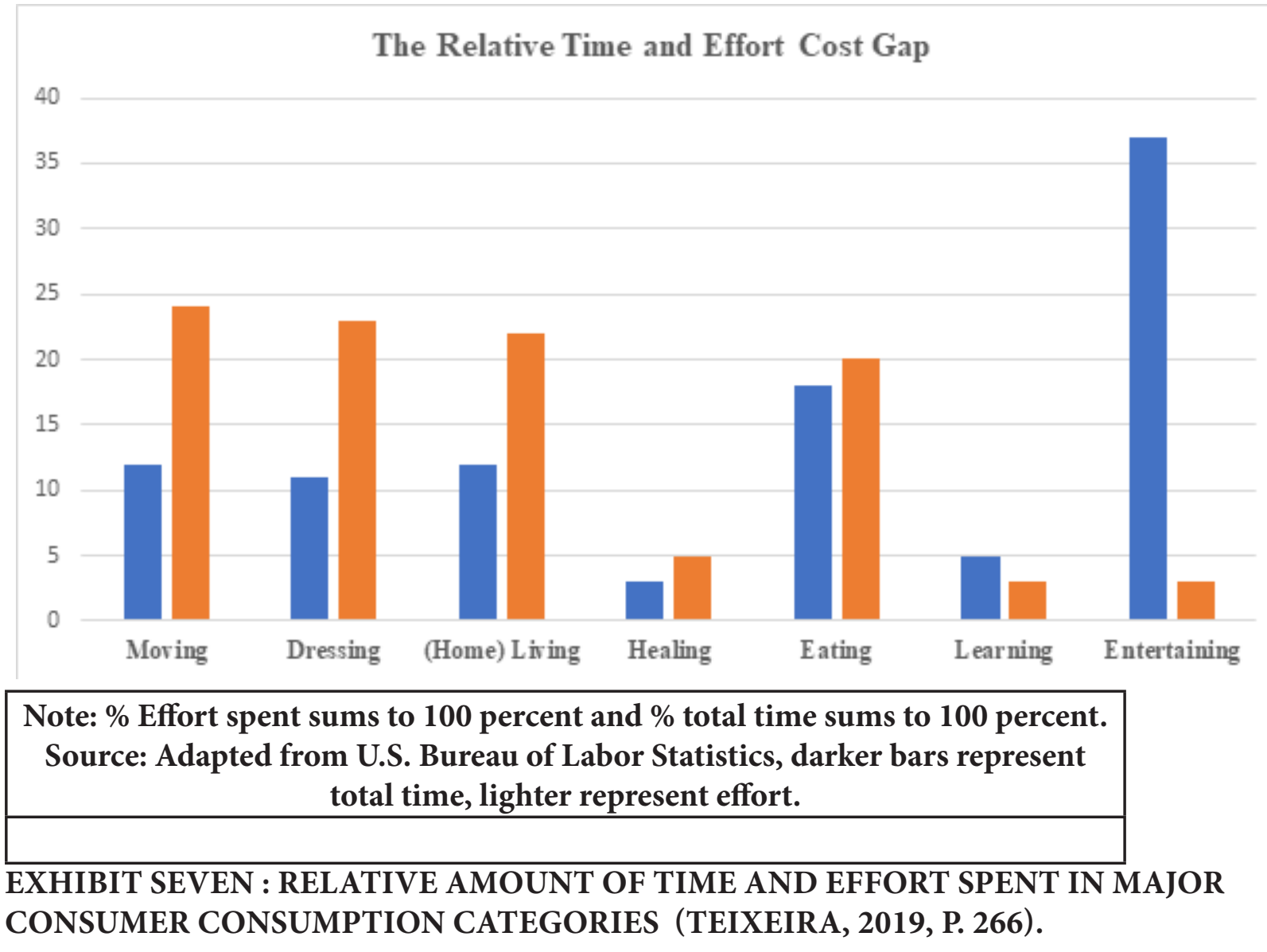




\section{MACRO ECONOMIC EFFECTS OF INNOVATIONS IN MARKETING}

The digital transformation of marketing not only effects the practices of individual companies and industries it has profound effects on the global macro-economic environment as well. The digital marketing strategies of using platform networks to reach target markets, reconfiguring value creating components of the product/service offering and innovative pricing has changed market dynamic not only within individual industries but across global markets as well. These macroeconomic effects have been widely discussed in the literature and will be summarized in this section (UNCTAD, 2019). Potential impacts include; the number and type of jobs available, distribution of income and wealth leading to greater income inequality, increased concentration within industries across a wide range of markets leading to potential monopoly effects, slower economic growth from income redistribution and types of investments due to digital economy, impact on taxation and government revenues.

In the previous section examples of the digital transformation of marketing were described in the context of basic marketing activities of value creation, value delivery and value capture as well as on competition with industries. But larger macro-economic effects exist that have far reaching implications for public policy. For example, in the previous section there were several examples of how retailers are adapting marketing practices given new digital technologies and business models. In America retailers are estimated to account for nearly 25\% of employment and retailing accounts for nearly $31 \%$ of global GDP. Digital technologies are having a major impact today and will have a greater impact going forward on the level of employment and skills necessary in retailing. Today automation and robotics are routinely used in warehouses to enhance performance and reduce labor costs; increasingly stores around the world are reducing labor content in store as well, through automated checkouts, customer service, replenishment, etc. Back office operations in purchasing, marketing analytics and sales are also being automated or using extensive AI assist which lowers labor deployed in these operations. New retail forms like Amazon Go and others utilize far fewer workers in a store than is traditionally used. Indeed, Amazon currently uses far fewer people to generate sales revenue than traditional retail operations. In addition to the number of workers the adaptation of digital marketing will change the skills needed to perform effectively. Currently this is a problem and even more so among less developed countries.

(UNCTAD, 2019, p. 96) reports that, "There are growing concerns that the increased use of various digital technologies will lead to job losses as human work is replaced by automation and AI." While employment effects have been frequently studied most have focused on joblosses and not job creation. Other global industries which have seen employment reductions due to digital transformation of marketing activities that include travel, transportation, advertising, customer service and broker/ sales networks. The report further states, "Digitalization is increasingly affecting routine tasks that are performed not just by less skilled workers, but also by middle-skilled workers, leading to a hollowing out of the middle class. Moreover, the increasing concentration of digital platforms may weaken the bargaining power of workers." This may be a factor which exacerbates growing income inequality which has both important political, social as well as economic impacts. (Stiglitz, 2016) and others have argued that growing income inequality is a threat to both economic growth and social wellbeing. Research from the (UNCTAD, 2019) found that growing digital markets may depress wages resulting in a lowering of consumer incomes across economies. Exhibit Eight below shows research an estimate of possible wealth redistribution due to digitization. 


\section{FIGURE 2: Global wealth will be redistributed due to digitalization}
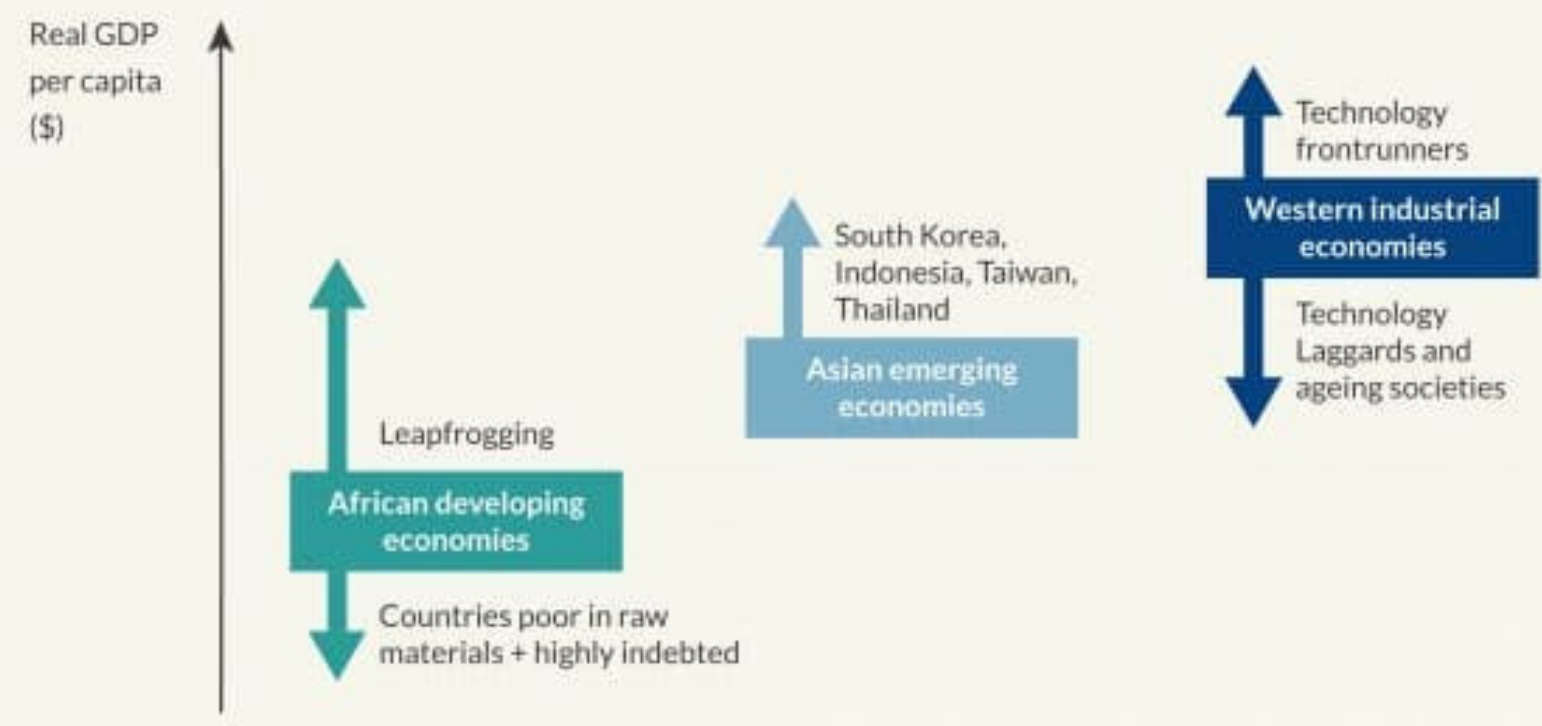

\section{EXHIBIT EIGHT: GLOBAL WEALTH REDISTRIBUTION DUE TO DIGITIZATION (PETERSON, 2019)}

The use of digital platforms aligned as networks that connect supplier, producers, intermediaries and customers also has potential impacts on competition and the competitiveness of nations. Because of the "Network Effect" marketing strategies and business model platforms become more valuable and perhaps more efficient given a larger network of users. These platform networks rely on vast amounts of data to develop and become efficient. Indeed, the digital landscape is dominated by a relative low number of business platforms, such as Google, Facebook, Amazon, Alibaba, etc. These digital platforms help to comprise economic ecosystems that are becoming increasing concentrated. These platform ecosystems are often characterized by relatively high fixed cost structures and very low marginal cost structures which offers huge scale benefits to firms with large networks. Those firms can leverage their fixed cost in algorithms, s/w ,etc. to enter new markets (Dawson et al., 2016). The market value of the world's top 70 platform companies is estimated in be over $90 \%$ concentrated in just two countries, China and the USA. In contrast, only about $4 \%$ of value of platform companies reside in the E.U.

There are concerns that these concentrated digital platforms may constitute monopolies that potentially could restrict innovation, increase network pricing power, create barriers to entry, disadvantage developing nations and smaller countries and lead to concentrations of political power of the networks. Multi-sided digital platforms may give firms the ability to cross subsidize products/services in new markets using infrastructure developed for other markets with little to new marginal costs. This shared cost structure allows pricing that can substantially undercut rivals. Thus, the go-to-market strategies of these firms have impact at the macro-economic level as well as the level of competition between firms. Understanding consumer benefits and costs can help to predict the macro impact of these platform networks. Thus, increasing concentration of large platform networks may have adverse effects on global competitiveness. Exhibit Nine below presents a model of how supply and demand networks by be affected by the digital economy. 
Digitization can disrupt industries when it changes the nature of supply, demand, or both.

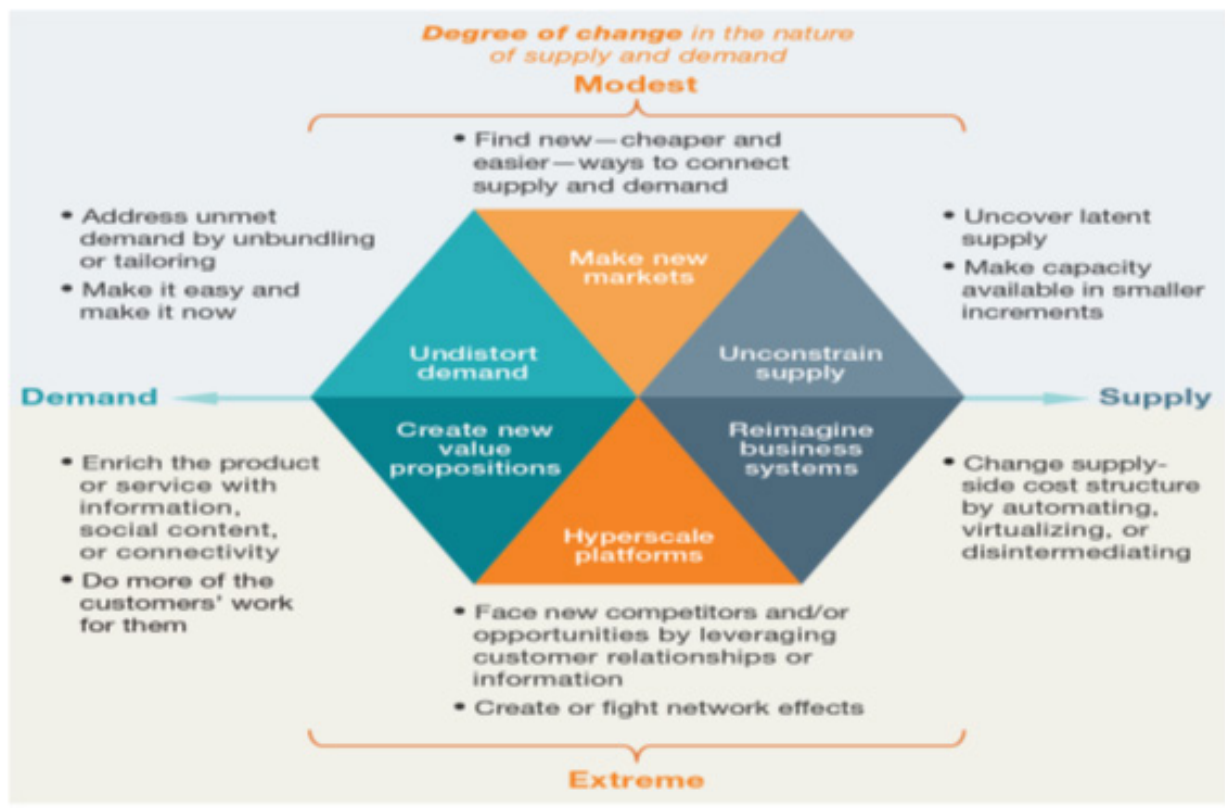

\section{EXHIBIT NINE: DIGITIZATION IMPACTS GLOBAL SUPPLY AND DEMAND ACROSS INDUSTRIES. (DAWSON ET AL., 2016)}

\section{DISCUSSION}

In reviewing the literature in marketing there is a consensus that marketing is entering an era of profound change where existing business models and consumer habits are being disrupted by new technology and new marketers using innovative marketing strategies. For example, (The World Economic Forum 2017) estimates that over the next decade that adaption of digital technologies could unlock nearly three trillion dollars in value to retailers over that decade due to increased consumer benefits and business cost savings. Of that total amount it estimates that the impact on consumers will comprise about $68 \%$ of the total benefits with the other $32 \%$ going to industry. The total amount of benefits is estimated to exceed two trillion dollar benefit to consumers over the next decade.

However, these consumer benefits are likely to be unevenly shared. Digital transformation of markets has been linked to greater income inequality. Research shows that wage income may be depressed with digitization and benefits shared more narrowly among highly skilled workers and investors. A greater percentage of global income and wealth is increasing concentrated in the top rungs of the pyramid. Some research suggests that increasing income inequality has attenuated rates of economic growth (Stigletz, 2016).

Marketing and business strategies leading to the creation of integrated "platform networks," may also create winners and losers leading to increasing concentration and power held my a few very large organizations. For example, in China the two leading platform networks control most of the nation's digital economic activity with networks that provide a wide range of digital services. Consumers have chosen to concentrate their use for convenience and the benefits of interconnected offerings. The larger these platform networks grow the powerful they become by offering users more connections, extracting useful information from vast troves of data and by offering lots of connections they increase the switching costs for users. These powerful digital platform ecosystems may foster monopoly effects of decreased innovation, reduced choice and bargaining power for buyers. "Companies like Apple, Tencent, and Google are blurring traditional industry definitions by spanning product categories and customer segments. Owners of such hyperscale platforms enjoy massive operating leverage from process automation, algorithms, and network effects created 
by the interactions of hundreds of millions, billions, or more users, customers, and devices... .Hyperscale platforms also create new barriers to entry, such as the information barrier created by GE Healthcare's platform, Centricity 360, which allows patients and third parties to collaborate in the cloud."(Chui et al., 2015). "In 2017, companies spent around $\$ 21.3$ billion through AIrelated mergers and investments - 26 times more than in 2015. All the largest platforms have major infrastructural footprints which represent another high barrier to entry for competitors" (UNCTAD, 2019, p. 87)

Along with new technology the marketing and entrepreneurial world is bubbling with new transformative business models that deploy new process and new technology to offer consumers greater value in their lives as well as to reduce retail costs. The merging of online and offline retail models with integration of technology using Omni-channel and another innovative business models will have profound impacts on which businesses thrive and which vanish from the competitive landscape. Increasingly firms are looking to decouple the consumer value chains by using shopping apps and digital technology that disrupt the business models of retail incumbents and provide value enhancements for shoppers. For example, Swiss watchmakers have been revamping distribution networks as consumers increasingly search for and buy products online." Other examples of the digital evolution business were given the World Economic Forum report (2017) to impact three areas of retail most significantly. The customer experience, technology like $\mathrm{AI} / \mathrm{AR}$ will enable a greater degree of personalization and there will be an increased focus instore on customer experience and as a showroom. A second trend will be a new era of consumer facing employees and technologies including the use of AI and greatly increased use of robots. One auto dealer we have worked with has moved its customer service operations to automated AI phone support and has received a much more positive customer response than with a human customer call center for customer service.

Large platform digital businesses also can create some tax problems for governments. For example, because of the intangible nature of service and the vagueness of market boundaries most income earned by these providers is reported by subsidiaries in low tax locales. Taxes are not always paid in the localities and from the people that generated revenue. Developing economies are particularly hard hit, with an estimated $\$ 100$ billion lost annually due to tax avoidance schemes by MNEs (UNCTAD, 2019, p95).

Exhibit Ten below overviews examples of government policies areas that should be reviewed in a world transformed by digital marketing and changing supply and demand economics.

These trends of new digital technologies and business models are pervasive and indeed gamechanging both for businesses and for public policy makers.

\section{Policy areas that need particular attention}

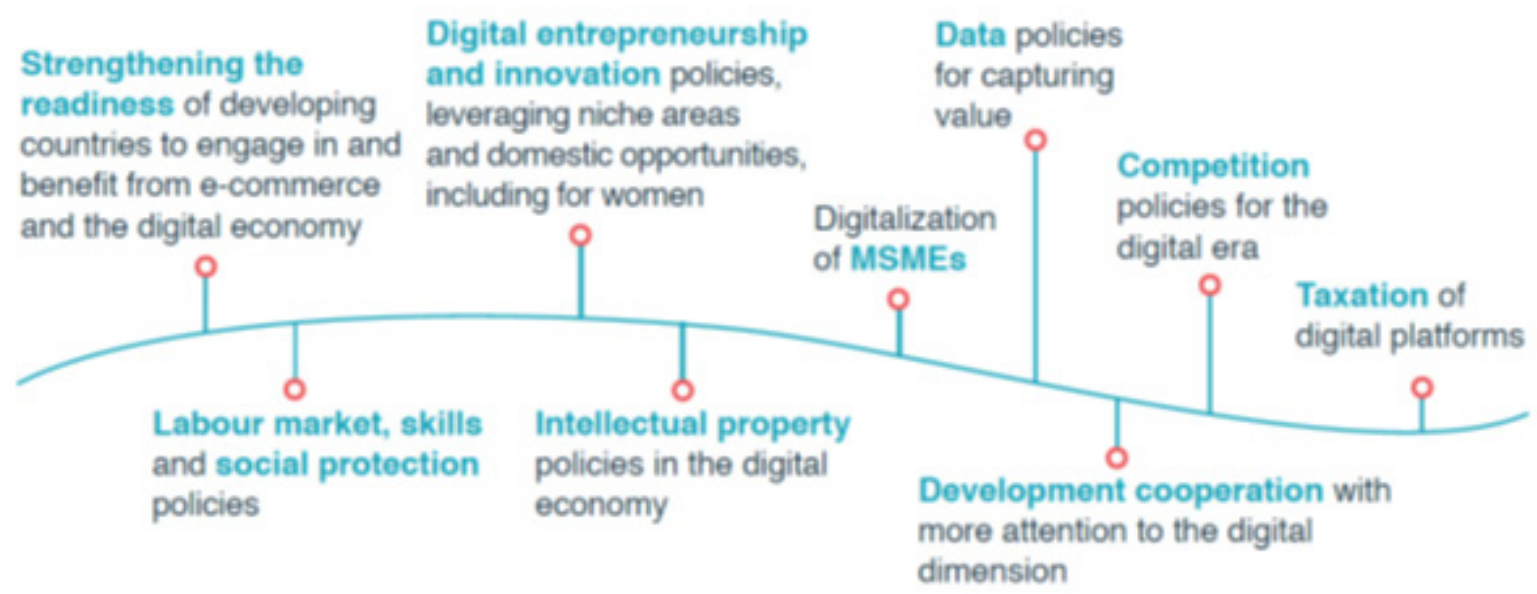

EXHIBIT: SUGGESTIONS FOR POLICY IN RESPONSE TO DIGITAL

TRANSFORMATION OF ECONOMY - UNCTAD, 2019 


\section{CONCLUSIONS}

This paper reviews the literature on digital disruption, marketing and innovation and has identified that buyer behavior is the most critical factor driving the evolution of economic demand today and into the future. Innovations in marketing practice are changing how firms assess demand and deploy new marketing strategies that have far reaching effects on competitiveness, consumer welfare and public policy decision-making. For marketing, digital disruption has had game changing impacts. Today, the nature of digital media such as more accurate metrics, combined with interactivity, have created whole new marketing opportunities. A critical challenge for marketers, technology providers and investors as well as government policy makers is how to predict the evolving preferences and desires of consumers.

The stakes are big. The landscape is littered with companies that failed to adapt to changing conditions brought about by new technology, business models and changing in demand. The rapid transformation of marketing with digital tools, product and strategies will hasten the adoption of digitization globally with impacts on labor markets, consumer welfare, and the competitiveness of both companies and nations. The digitization transformation of marketing is expected to create uneven benefits and costs for consumers, businesses and nations.

Traditional marketing methods used to understand consumer behavior have proven to be less useful in a world transformed by digital markets. Consumer shopping and purchase behavior is rapidly evolving with increased preferences for shared consumption over ownership, use of mobile technology, consumer co-creation of value, online shopping and an increased preference for experiences over material things among the many changes in preferences. This has led to the development of new models such as the Consumer Decision Journal and Consumer Value Chain models to better assess the nature of consumer demand. Moeller et al. (2018) state, "The constraint for your company will not be the technology. It will be your ability to bring the three drivers to bear: to lower costs, engage customers, and make better use of assets. If you can employ digital technology to do that effectively, you will be among the winners of the age of digital disruption."

This research also calls for the development of new ways to understand consumer preferences and the evolution of those preferences. Initiatives such as MITs "Open Voice Network," which seeks to better understand technology, policy and consumer preferences for the use of voice technology (i.e. Alexa; Google Home) and engages both universities and industry should be encouraged. Organizations and policy makers need to address how the digital transformation of marketing will affect economic competitiveness and consumer welfare. Both companies and public policy makers need to "follow the consumer" to gain insights on how to best adapt business strategies and governmental policies to best operate in this new digital economy. 


\section{REFERENCES}

[1] Baldwin, Richard (2016) The Great Convergence: Information Technology and the New Globalization, Belknap Harvard.

[2] Berkshire Hathaway Businesswire 2016.

[3] Bettiol, Marco; Mauro Capestro and Eleonora Di Maria (2017) Industry 4.0: The Strategic Role of Marketing, working paper, Dipartimento di Scienze Economiche e Aziendali "Marco Fanno"

[4] Buckley, Patricia and Rumki Majundar (2018) "The services powerhouse: Increasingly vital to world economic growth," Delloitte Insights (July). https://www2.deloitte.com/us/en/insights/ economy/issues-by-the-numbers/trade-in-services-economy-growth.html

[5] Castro-Leon, Enrique and Robert Harmon (2016) Cloud as a Service: Understanding the Service Innovation Ecosystem, Apress.

[6] Chui, Michael and James Manyika, "Competition at the digital edge: 'Hyperscale' businesses," McKinsey Quarterly, March 2015, mckinsey.com.

[7] Cui, A.S. and F. Fu (2016) Utilizing customer knowledge in innovation: antecedents and impact of customer involvement on new product performance, Journal of the Academy of Marketing Science, V.44, N.4.

[8] Dawson, Angus, Martin Hirt, and Jay Scanlan (2016) The Economic Essentials of Digital Strategy, McKinsey Quarterly (March)

[9] Digital Marketing Institute (2019) How Is Digital Transformation Changing Marketing?

[10] Drucker, Peter F. and J.A. Maciariello (2008). Management: Revised Edition, New York: Harper Collins.

[11] Erkişi, Kemal ve Semra Boğa (2019)"High-Technology Products Export and Economic Growth: a Panel Data Analysis for EU-15 Countries," Bingöl Üniversitesi Sosyal Bilimler Enstitüsü Dergisi, Volume: 9, N.18 (Autumn) 669-683.

[12] Foote, Caleb (2019) Fact of the Week: The Digital Economy Grew 4.3 Times Faster than the U.S. Economy Overall from 1997 to 2017, Information Technology \& Innovation Foundation, (April, 15).https://itif.org/publications/2019/04/15/fact-week-digital-economy-grew-43-times-faster-useconomy-overall-1997-2017

https://digitalmarketinginstitute.com/blog/how-is-digital-transformation-changing-marketing https://www.ineteconomics.org/uploads/papers/Paper-Turner-Capitalism-in-the-Age-of-Robots. pdf

[13] Kagermann, Henning (2015) "Change Through Digitization-Value Creation in the Age of Industry 4.0," in Management of Permanent Change, DOI: 10.1007/978-3-658-05014-6_2

[14] Kahn, Barbara (2018) The Shopping Revolution, Wharton Digital Press.

[15] Katz, Raul 1. (2017) Social and Economic Impact of Digital Transformation on the Economy, ITU/ BDT Regulatory and Market Environment Division.

https://www.itu.int/en/ITU-D/Conferences/GSR/Documents/GSR2017/Soc_Eco_impact_ Digital_transformation_finalGSR.pdf

[16] Kenney, Martin; Petri Rouvinen and John Zysman (2015) Digital Disruption and its Societal Impacts, Journal of Industry, Competition and Trade, March 2015, Volume 15, Issue 1, pp 1-4.

[17] Lorenzo Ardito, Antonio Messeni Petruzzelli, Umberto Panniello, Achille Claudio Garavelli, (2019) “Towards Industry 4.0: Mapping digital technologies for supply chain management-marketing integration", Business Process Management Journal, Vol. 25 Issue: 2, pp.323-346.

[18] Martin Hirt and Paul Willmott (2014) Strategic principles for competing in the digital age, McKinsey Quarterly (May).

[19] Mićić, Ljubiša (2017) Digital Transformation and its Influence on GDP, Economics, Vol. 5, N.2. 135-147.

[20] Moeller, Leslie, Nick Hodson and Martina Sangin (2018), The Coming Wave of Digital Disruption, Strategy and Business (90). 
[21] OECD Report (2018) Implications of the Digital Transformation for the Business Sector, Conference held in London UK, 8-9 November. http://www.oecd.org/sti/ind/digital-transformationbusiness-sector-summary.pdf

[22]Petersen, Thieß (2019) Digital Economy: How is digitalization changing global competitiveness and economic prosperity? Blog: https:/ged-project.de/blogpostsen/digital-economy-how-is-digitalizationchanging-global-competitiveness-and-economic-prosperity/

[23] Rifkin, Jeremy (2015) The Zero Marginal Cost Society, St. Martin’s Griffin, New York.

[24] Stiglitz, Joseph (2016), adapted from Rethinking Capitalism: Economics and Policy for Sustainable and Inclusive Growth, Wiley-Blackwell. https://evonomics.com/joseph-stiglitz-inequality-unearnedincome/[25] Straub, Richard (2019) World Economic Forum report; , McKinsey research; http:// www.marketingjournal.org/the-power-of-ecosystems-an-interview-with-richard-straub/

[26] Teixeira, Thales (2019) Unlocking the Customer Value Chain, Currencybooks.com, New York.

[27] Turner, Adair (2018) Capitalism in the age of robots: work, income and wealth in the 21st-century, Lecture at School of Advanced International Studies, Johns Hopkins University (April)

https://www.ineteconomics.org/uploads/papers/Paper-Turner-Capitalism-in-the-Age-of-Robots.pdf [28] UN News (2017) Branding and other intangibles account for 30 per cent of product value - UN report (November), https://news.un.org/en/story/2017/11/636712-branding-and-other-intangiblesaccount-30-cent-product-value-un-report

[29] Vaitheeswaran, Vijay (2007) "Something new under the sun: A Special report on innovation," The Economist, quoting Richard Lyons, October 13th, pg. 4.

[30]World Economic Forum (2017) Shaping the Future of Retail for Consumer Industries, https:// www.weforum.org/reports/shaping-the-future-of-retail-for-consumer-industries 